Revista Arbitrada Interdisciplinaria KOINONIA

Año VII. Vol VII. N¹3. Enero - Junio. 2022

Hecho el depósito de Ley: FA2016000010

ISSN: $2542-3088$

FUNDACIÓN KOINONIA (F.K). Santa Ana de Coro. Venezuela.

Dra. Jinette Gabriela Labrador Fernández

http://dx.doi.org/10.35381/r.k.v7i13.1620

\title{
Cambios en las perspectivas investigativas postpandemia en las Ciencias Sociales
}

El domingo 30 de enero de 2022 se cumplieron dos años desde que el director general de la Organización Mundial de la Salud (OMS), Dr. Tedros Adhnom Ghebreyeus, declaró una emergencia de salud pública de magnitud internacional, debido a la propagación de la enfermedad por Coronavirus (COVID-19). Para ese entonces, habían menos de cien casos y sin ninguna notificación de muerte.

No obstante, para el 3 de noviembre de 2020 la BBC NEWS/Mundo anunciaba la velocidad de propagación del virus en su variante SARS-Cov2 por Europa, en la cual, hubo un intenso y alarmante incremento en muertes, específicamente, el $40 \%$ en una semana-según la OMS. En la trayectoria histórica del paso del virus en el ser vivo, en especial, en el ser vivo humano, se han dado a conocer a la población mundial casi 350 millones de casos y más de 5,5 millones de defunciones.

Para la semana del 17 de enero de 2022 ante la oficina de la OMS se informaba una media de 100 casos cada tres segundos y alguien moría por COVID-19 cada 12 segundos. Asimismo, desde que se dio a conocer OMICRON por primera vez, finales de noviembre, principios de diciembre de 2021, se ha notificado a la OMS 80 millones de casos, donde el estallido de estos no se ha convertido en un acrecentamiento de fallecimientos.

Estos acontecimientos y hechos desde el 2019 hasta la actualidad, han llevado al hombre/mujer de ciencia, como a educadores, empresarios, vendedores ambulantes, etc., a buscar herramientas, invenciones y soluciones, bien sea desde la investigación en las ciencias naturales, sociales, así como, en la dimensión pedagógica, psicológica, epidemiológica, sociológica, antropológica, filosófica, de salud, o simplemente en el 
Revista Arbitrada Interdisciplinaria KOINONIA

Año VII. Vol VII. ํำ13. Enero - Junio. 2022

Hecho el depósito de Ley: FA2016000010

ISSN: $2542-3088$

FUNDACIÓN KOINONIA (F.K). Santa Ana de Coro. Venezuela.

Dra. Jinette Gabriela Labrador Fernández

quehacer social para poder recrear la vida en el nicho ecológico que sostiene a la humanidad y la hace posible.

Tal recreación se hizo y se hace viable mediante el conocimiento, éste puede ser en un inicio común o "vulgar" que posteriormente puede ser científico. Esto es, en los inicios de la pandemia, resultó abrupta la situación que se estaba viviendo: deceso de familiares y amigos, descrecimiento económico, aislamiento, etc., que condujo accidentalmente a modos de poder continuar con la producción económica, política, social, educativa y de salubridad en los países. Existía una desinformación acerca de la COVID-19, o informaciones vagas o ambiguas estableciendo redes de conversaciones basadas en hipótesis que con el tiempo se fueron rechazando. Este tipo de conocimiento como plantea Arias (2012):

Es un tipo de saber cotidiano que surge de la opinión o de la experiencia particular de los individuos. En la mayoría de los casos se adquiere de forma casual y no intencional. En consecuencia, es un conocimiento no verificado, que se transmite de generación en generación permaneciendo en forma de falsa creencia. No obstante, en algunas oportunidades, el conocimiento vulgar puede servir de base para la construcción del conocimiento científico, debido a que una creencia puede ser investigada y posteriormente comprobada ( $p$. 14).

Así, muchos fueron los colegios, universidades, tecnológicos que emprendieron a ciegas una educación virtual resultando en los primeros pasos que niños, jóvenes y adultos utilizaran redes sociales como WhatsApp para enviar trabajos, clases mediante imágenes acompañadas con notas de voz; paulatinamente se fueron dando cursos de formación a docentes, padres y representantes para saber cómo diseñar, implementar y evaluar a los discentes en lo que se empezó a distinguir como "nueva normalidad".

Por consiguiente, es en esa dinámica relacional entre el observador cognoscente con el otro, la otra, lo otro que hace que ocurra ese proceso investigativo transformando una idea o creencia en un conocimiento científico. Éste "es un saber producto de una investigación en la que se ha empleado el método científico. Tal condición le confiere 
características que lo hacen verificable, objetivo, metódico, sistemático y predictivo" (Arias, 2012, p. 14). De esta manera, la investigación en las ciencias sociales ya daba cambios en plena pandemia, por ejemplo, Alvarado-Peña y colaboradores (2021) describieron la realidad y perspectivas de los Centros de Investigación Universitarios en América Latina ante el Covid19, en la que concluyeron que estas instituciones han salido adelante, en momentos de pandemia, "incorporando los medios digitales a sus actividades y aprovechando las oportunidades aperturadas a nivel internacional para el mundo de la ciencia y seguir produciendo conocimiento direccionado a lograr el desarrollo socio-productivo de los países" (p. 436). Por lo tanto, la finalidad de la investigación se sustenta en ampliar la experiencia cognitiva mediante la explicación y profundización de fenómenos; desarrollar teorías, establecer principios; formular y reformular planteamientos, refutar resultados.

De otra parte, Mejía y Velázquez (2021) asumieron una "perspectiva comprensivista de las ciencias sociales, desde autores que debaten la racionalidad técnico-instrumental y que plantean, en contraposición, la necesidad de una racionalidad práctico-reflexiva tanto en la práctica profesional como en la formación en Trabajo Social" (p. 324). Asimismo, hubo cambio en la concepción y practica en las técnicas de obtención de información en investigaciones cualitativas utilizando las TIC para la realización de entrevistas y grupos de enfoque. A saber, muchas viviendas se convirtieron en oficinas, gimnasios, colegios, entre otros. La convivencia familiar se tornó compleja, algunas veces, las relaciones se tornaron violentas.

En tal sentido, los cambios señalados hasta ahora durante la pandemia, como otros: convocatorias para proyectos que permitieron entender la situación, medios de comunicación académica y científica se unieron abriendo sus plataformas que brindaron cobertura y acceso a expertos e investigadores; CLACSO (Consejo Latinoamericano de Ciencias Sociales), inauguró un observatorio social del coronavirus denominado "Pensar la Pandemia", donde prestigiosos académicos, investigadores y pensadores de las 
ciencias sociales se unieron en la proposición desde distintas aristas como la educación, los procesos políticos y sociales, el territorio, la cultura, entre otras.

Por otra parte, se está hablando de los cambios en las perspectivas investigativas postpandemia en las Ciencias Sociales; pero, ¿qué se está distinguiendo por postpandemia?, ¿será que es el cese de este virus que tantas vidas humanas sea llevado?, ¿habrá la vacuna contra el COVID-19 erradicado para siempre el virus? Según el Diccionario de la Lengua Española (2021), el prefijo post significa "detrás de" o "después de" y el término pandemia desde la mirada médica "Enfermedad epidémica que se extiende a muchos países o que ataca a casi todos los individuos de una localidad o región"; en consecuencia, la postpandemia implica que las personas no son las mismas de ayer, de antes de la pandemia: autómatas de lo material; competitivos donde se irrespeta la legitimidad del otro, la otra; la negación de aquellos con quienes se comparte. Es decir, después de esta pandemia, o viviendo con ella, la postpandemia implica tomar conciencia por medio del proceso de autoobservación, la reflexión del ser humano en cómo es que hace lo que hace. La reflexión del ser en su relación con el nicho ecológico que lo hace posible.

Por ende, además de la autoobservación, otro cambio en la perspectiva investigativa postpandemia en las ciencias sociales es la flexibilización en la obtención de información en la investigación tanto cuantitativa como cualitativa, ya que, se ha evidenciado en muchos estudios el ingenio y la credibilidad de los resultados mediante la utilización de las TIC.

Por último, un cambio en las redes de conversaciones hacia un proyecto global colaborativo en la que se entienda que aprender a convivir con la COVID-19 no puede significar que demos rienda suelta al virus. No puede significar la aceptación de casi 50 000 defunciones por semana debidas a una enfermedad prevenible y tratable. No puede significar la aceptación de una carga inadmisible sobre nuestros sistemas de salud, cuando cada día, trabajadores sanitarios exhaustos concurren una vez más a la primera línea de batalla. No puede significar que ignoremos las consecuencias de la COVID-19 
Revista Arbitrada Interdisciplinaria KOINONIA

Año VII. Vol VII. N¹3. Enero - Junio. 2022

Hecho el depósito de Ley: FA2016000010 ISSN: 2542-3088

FUNDACIÓN KOINONIA (F.K). Santa Ana de Coro. Venezuela.

Dra. Jinette Gabriela Labrador Fernández

prolongada, que aún no conocemos cabalmente. No puede significar que apostemos a un virus cuya evolución no podemos controlar ni predecir (Adhnom Ghebreyeus, 2022, p.

1)

En resumen, los cambios en la perspectiva investigativa postpandemia en las Ciencias Sociales contemplan tres aspectos:

a) Autoobservación

b) Flexibilización en la obtención de información

c) Conversaciones de un proyecto global colaborativo

Dra. Dinette Gabriela Labrador Fernández

inettelabrador@gmail.com

Universidad del Zulia, Zulia

Venezuela

https://orcid.org/0000-0002-9475-6524 
Dra. Jinette Gabriela Labrador Fernández

\section{REFERENCIAS CONSULTADAS}

Alvarado, L., Amaya, R., Sansores, E. y Rafael, A. (2021). Realidad y perspectivas de los Centros de Investigación Universitarios en América Latina ante el COVID-19 2021 [Reality and perspectives of University Research Centers in Latin America before COVID-19 2021]. Telos: revista de Estudios Interdisciplinarios en Ciencias Sociales, 23(2), 435-449. DOI: www.doi.org/10.36390/telos232.14

Arias, F. (2012). El proyecto de investigación [The research project]. (6 ed.). Caracas. Episteme.

Mejía, X. y Velásquez, P. (2021). Cambios generados por la COVID-19 en la práctica formativa e investigativa en Trabajo Social: oportunidades, dilemas y retos para la investigación social [Changes generated by COVID-19 in training and research practice in Social Work: opportunities, dilemmas and challenges for social research]. Alternativas. Cuadernos de Trabajo Social, 28(2), 325-349, doi:https://doi.org/10.14198/ALTERN2021.28.2.08.

Organización Mundial de la Salud. (24 de enero de 2022). Alocución de apertura del Director General de la OMS en la 150. a reunión del Consejo Ejecutivo [Opening address by the Director-General of WHO to the 150th session of the Executive Board]. https://n9.cl/coegp

Real Academia Española. (2021). Post . En Diccionario de la Lengua Española. Recuperado el 16 de febrero de 2022, de https://dle.rae.es/pos-?m=form

Real Academia Española. (2021). Pandemia [Pandemic]. En Diccionario de la Lengua Española. Recuperado el 16 de febrero de 2022, de https://dle.rae.es/pandemia?m=form 